\title{
MANDIBULAR RANGE OF MOTION AND ITS RELATION TO TEMPOROMANDIBULAR DISORDERS
}

\author{
Vassil Svechtarov ${ }^{1}$, Miriana Hristova ${ }^{2}$, Savina Nencheva-Svechtarova ${ }^{3}$, Tsvetan Tonchev ${ }^{4}$ \\ ${ }^{1}$ Department Oral and Maxillofacial Surgery, Faculty of Dental Medicine, \\ Medical University of Sofia \\ ${ }^{2} D M D$, Status Dental Clinic, Dobrich \\ ${ }^{3} D M D$, Center for Integrated Dental Medicine, Faculty of Dental Medicine, \\ Medical University of Sofia \\ ${ }^{4}$ Department Oral and Maxillofacial Surgery and Special Dental Imaging, \\ Faculty of Dental Medicine, Medical University of Varna
}

\begin{abstract}
INTRODUCTION: One of the most important signs and symptoms of temporomandibular disorders (TMD) is deviation or restriction in the mandibular range of motion. Limited or increased movement is considered as a sign of dysfunction, so measurement and evaluation of mandibular movement ranges are considered important parameters within the clinical examination and a significant component in the treatment and follow up of the temporomandibular disorders.

MATERIAL AND METHODS: A total of 34 articles are included in this comprehensive review of the relevant studies on mandibular range of motion related to temporomandibular disorders. This review provides summarized clinical and cephalometric analyses focused on the three planes of the mandibular range of motion used in all classifications and diagnostic criteria for temporomandibular disorders.

RESULTS AND CONCLUSION: The majority of the studies show variations in the degree of mandibular movements in patients with TM pathology. This review of the literature presents a synthesized version of the basic parameters of the mandibular movements that can be considered in the diagnosis of temporomandibular disorders in accordance with the postulates of the relevant research and diagnostic criteria.
\end{abstract}

Keywords: mandibular range of motion, temporomandibular disorders, RDC/TMD, interincisal distance

\section{INTRODUCTION}

Muscle and TMJ disorders are often causes of limited mandibular movements. Some studies have pointed to significant differences in mandibular

\footnotetext{
Address for correspondence:

assoc. prof. Vassil Svechtarov

Department Oral and Maxillofacial Surgery

Faculty of Dental Medicine

Medical University of Sofia

1 G. Sofiiski Blvd.

1431 Sofia, Bulgaria

e-mail:vassilsvechtarov@yahoo.com
}

Received: January 15, 2015

Accepted: May 21, 2015 movement between asymptomatic subjects and patients with TMD. One of the most important signs and symptoms of TMD according to the American Dental Association is deviation or restriction in the mandibular range of motion. Limited or increased movement is considered as a sign of dysfunction, so measurement and evaluation of mandibular movement ranges is an important parameter within the clinical examination and a significant component in the treatment and follow up of the temporomandibular disorders. According to the condensed version of Research Diagnostic Criteria for the Temporomandibular Disorders (RDC/TMD), myofascial pain with limited opening group requires pain-free unas- 
sisted opening $<40 \mathrm{~mm}$ and passive stretch $\geq 5 \mathrm{~mm}$; for Disc displacement without reduction with limited opening group - unassisted opening (even painful) $\leq 35 \mathrm{~mm}$ and passive stretch $\leq 4 \mathrm{~mm}$ and contralateral excursion $<$ mm or uncorrected ipsilateral deviation on opening; Disc displacement without reduction without limited opening group requires unassisted opening (even painful) $>35 \mathrm{~mm}$ and passive stretch $>4 \mathrm{~mm}$ and contralateral excursion $\geq 7 \mathrm{~mm}$ (12).

\section{DEFINITIONS}

Normal mouth opening has been defined either as the interincisal distance or as the interincisal distance plus the overbite. Interincisal opening has been defined as "the greatest distance between the incisal edge of the maxillary central incisors to the incisal edge of the mandibular central incisors at the midline when the mouth is open as wide as possible. Measurement of the interincisal distance plus overbite means measurement of the vertical distance traveled by the mandible. An advantage of the incisal edge distance measurement is that the measuring point is relatively more permanent and more easily determined. $(1,22,25)$ Measurements using a millimeter ruler have been used for assessment of mandibular mobility in large population studies, and measurement reliability has been shown to be very $\operatorname{good}(21)$.

\section{VERTICAL RANGE OF MOTION}

There is a wide range of values of mouth-opening capacity that are considered to be normal. Values from $32 \mathrm{~mm}$ to $77 \mathrm{~mm}$ have been reported in the literature for adults. Severely restricted mouth opening may occur as a result of intra or extra capsular pathology of the TMJ. Studies of asymptomatic subjects demonstrated that $1.2 \%$ of young adults and $15 \%$ of an elderly group opened their mouth less than $40 \mathrm{~mm}$ (23). The average intrinsic vertical mouth opening measures $40-50 \mathrm{~mm}$, an opening of $25-35 \mathrm{~mm}$ is functional, and $10-24 \mathrm{~mm}$ is severely limiting. (14) The cutoff values for restricted opening are less than $40 \mathrm{~mm}$ for muscular disorders and less than $35 \mathrm{~mm}$ for joint-related disorders (12). Some researchers judge the opening to be limited if the interincisal distance is $<40 \mathrm{~mm}$. Whereas other investigators consider $<35 \mathrm{~mm}$ for men and $<30$ for women as restricted opening (14). Landtwing (20) stated that $36-38 \mathrm{~mm}$ incisal edge distance is regarded as the minimal limit for adultsq while some other researchers report as normal an average maximum opening of $43.4 \mathrm{~mm}$. Ingervall (17) recorded a value of $52 \mathrm{~mm}$ (range 33-65 mm), while Agerberg (1) found the mean to be $58.6 \mathrm{~mm}$ (range $44-77 \mathrm{~mm}$ ) in men and $53.3 \mathrm{~mm}$ (range $42-75 \mathrm{~mm}$ ) in women. Travers et al. (31) found a mean value of $46.6 \mathrm{~mm}$ for women. According to Bumann (5) the mean of normal mouth opening averages $53-58 \mathrm{~mm}$. Uzunov et al. (33) investigated the range of interincisal opening among the Bulgarian population. The study comprised of 100 subjects with equal male to female ratio i.e. 50 of each, and age range $18-50$ years. The average mouth opening of males was $51.76 \mathrm{~mm}$, and of females $-47.56 \mathrm{~mm}$. The minimum/maximum mouth opening of males was $33.51 \mathrm{~mm} / 69.20 \mathrm{~mm}$, and of females $-25.26 \mathrm{~mm} / 59.00 \mathrm{~mm}$.

Research has shown that the measurement of mouth opening varies significantly with age, gender and race. The significant difference of values between men and women is likely due to the differences in anatomic cha0racteristics between the genders. Men have a tendency to open on average $5 \mathrm{~mm}$ more than women (29). According to Cortese (9) measurements range from $40 \mathrm{~mm}$ to $77 \mathrm{~mm}$ in men, with more frequent values around $50-60 \mathrm{~mm}$, and from $32 \mathrm{~mm}$ to $75 \mathrm{~mm}$ in women, with more frequent values around $45-55 \mathrm{~mm}$. Travell (31) found that the average maximum opening value was $59 \mathrm{~mm}$ (range 50 to $73 \mathrm{~mm}$ ) in men and $53 \mathrm{~mm}$ (range 45 to $65 \mathrm{~mm}$ ) in women. He concluded that the average normal maximum opening should not be less than $50 \mathrm{~mm}$ for men and $45 \mathrm{~mm}$ for women. The results of Rosenbaum (29) were similar, with an average maximum opening of $44.9 \mathrm{~mm}$ in the adults. Rieder (28) found that the mean maximum mouth-opening was between 40-60 $\mathrm{mm}$ in men and $35-55 \mathrm{~mm}$ in women. A research by Kardari (18) showed maximum mouth opening values slightly higher in women than in men. Ingervall's findings (16) suggest that the maximum jaw opening varies depending on the length of the mandible, the length of the anterior cranial base and ramus inclination. Maximum mouth-opening significantly increase when the overjet exceeded $5 \mathrm{~mm}$. Excessive or even negative overjet is positively associated with TMJ pain. The subjects with an overjet of more than 
Vassil Svechtarov, Miriana Hristova, Savina Nencheva-Svechtarova

$5 \mathrm{~mm}$ show a mean mouth opening of $44 \mathrm{~mm}$ instead of $42 \mathrm{~mm}$ observed in subjects with smaller overjet. Subjects with a normal or greater overbite exhibited a smaller maximum opening capacity compared to those with small overbite or open bite. Racial differences are believed to affect the degree of mouth opening. Mouth opening values of Asians seem to be smaller than those of Caucasians (13). According to Kitsoulis et al. (19) the mean mouth opening in Greeks (aged 18-26 yrs, mean 19.6 yrs) was: 46.56 $\mathrm{mm}$ in men, $44.43 \mathrm{~mm}$ in women and $45.09 \mathrm{~mm}$ for the overall population. For Arabic population the lowest mean value for males is between the ages of 40 and 50 years $(41.15 \mathrm{~mm})$, and for females at the age of 30 to 40 years $(33.45 \mathrm{~mm})$. Yao et al. (34) found for the Chinese population that maximal unassisted mouth opening (MMO) significantly decreased with the increasing of age. The average $\mathrm{MMO}$ values were $51.11 \pm 6.47 \mathrm{~mm}$ for the young, $48.45 \pm 5.76 \mathrm{~mm}$ for the middle age and $46.62 \pm 5.71 \mathrm{~mm}$ for the senior age groups. For every 10 yrs MMO decreased by about $1.4 \mathrm{~mm}$ in men and $0.9 \mathrm{~mm}$ in women. For the age range of 20-80 years, the authors gave the following regression equation: $\mathrm{MMO}(\mathrm{mm})=56.60-0.14 \mathrm{x}$ age, for males; and MMO $(\mathrm{mm})=52.33-0.09 \mathrm{x}$ age, for females. They concluded that gender and age had significant influences on the MMO value and age was a significant predictor of $\mathrm{MMO}$ measurements.

LATERAL AND PROTRUSIVE RANGE OF MOTION

Lateral movements of less than $8 \mathrm{~mm}$ are classified as restricted (some authors set the cut-off point

Table.1. Range of mandibular movements of asymptomatic men and patients with muscle and TMJ disorders (7)

\begin{tabular}{|c|c|c|c|c|c|c|c|c|}
\hline \multirow[b]{2}{*}{ Age of all groups : $19-28 \mathrm{yrs}$} & \multicolumn{2}{|c|}{ Mouth opening $\mathrm{mm}$} & \multicolumn{2}{|c|}{ Right lateral shift mm } & \multicolumn{2}{|c|}{ Left lateral shift $\mathrm{mm}$} & \multicolumn{2}{|c|}{ Protrusion $\mathrm{mm}$} \\
\hline & Range & Mean & Range & Mean & Range & Mean & Range & Mean \\
\hline Control group & $40-61$ & $49.89 \pm 5.27$ & $4-14$ & $8.36 \pm 2.46$ & $3-14$ & $8.34 \pm 2.49$ & $3-11$ & $6.16 \pm 1.90$ \\
\hline Muscle disorder group & $35-56$ & $46.47 \pm 5.10$ & $2-12$ & $7.10 \pm 2.06$ & $3-12$ & $7.47 \pm 2.03$ & $2-8$ & $5.57 \pm 1.70$ \\
\hline $\begin{array}{l}\text { Disc displacement with reduction } \\
\text { group }\end{array}$ & $36-57$ & $46.97 \pm 5.05$ & $3-12$ & $7.10 \pm 2.45$ & $3-11$ & $7.00 \pm 2.08$ & $3-9$ & $5.17 \pm 1.62$ \\
\hline $\begin{array}{l}\text { Disc displacement with } \\
\text { reduction, associated with muscle } \\
\text { disorder }\end{array}$ & $37-58$ & $47.93 \pm 5.60$ & $3-11$ & $6.87 \pm 2.19$ & $3-11$ & $6.97 \pm 2.95$ & $2-8$ & $4.87 \pm 1.61$ \\
\hline $\begin{array}{l}\text { Total in asymptomatic and TMD } \\
\text { patients groups }\end{array}$ & $35-61$ & $47.82 \pm 5.26$ & $2-14$ & $7.69 \pm 2.43$ & $3-14$ & $7.74 \pm 2.38$ & $2-11$ & $5.68 \pm 1.84$ \\
\hline
\end{tabular}

Scripta Scientifica Medicinae Dentalis, vol. 1, №1, 2015, 21-26

Copyright (๑) Medical University of Varna 
ity of healthy people and TMD patients could move their jaw more to the left. The mean absolute difference between left and right movement (in $\mathrm{mm}$ ) was 1.24 among healthy females, and 2.09 among healthy males. In the TMD group, the corresponding values were 2.62 and 2.83 , respectively. In healthy subjects, the mean ratio between opening and left excursion was 5.0, and between opening and right excursion was 5.5. In a TMD group, the corresponding values were 4.6 and 6.1. The authors concluded that moderate deviations from symmetric movements (mean: $1.2 \mathrm{~mm}$ for women, $2.1 \mathrm{~mm}$ for men) appeared to be the norm even in healthy individuals.

In the studies by Celic et al. $(7,8)$ the statistically significant differences in the range of mandibular movements clearly separated asymptomatic men and patients with muscle and TMJ disorders:
Blečić et al. (4) stated that myofacial pain had a huge influence on mandibular mobility. They observed a significant difference between patients with myofacial pain of the masticatory muscles and healthy controls in relation to unassisted opening without pain, maximal unassisted opening, assisted opening and protrusion:

De Leeuw et al. (10) observed that:

* a. Mandibular movement capacity was more often restricted in joints of the reducting disc displacement (RDD) and non-reducting disc displacement (NRDD) group than in joints of the control group.

* b. The mean maximal mouth opening was significantly larger in controls than in patients.

* c. No differences between patients and controls were found in horizontal movement rang-

Table. 2. Mandibular movements in patients with myofacial pain of the masticatory muscles and healthy controls (4)

\begin{tabular}{|c|c|c|c|c|c|c|}
\hline Movements in $\mathrm{mm}$ & $\begin{array}{l}\text { Unassisted } \\
\text { opening } \\
\text { without } \\
\text { pain }\end{array}$ & $\begin{array}{c}\text { Max. } \\
\text { unassisted } \\
\text { opening }\end{array}$ & $\begin{array}{l}\text { Assisted } \\
\text { opening }\end{array}$ & $\begin{array}{c}\text { Right } \\
\text { excursion }\end{array}$ & $\begin{array}{c}\text { Left } \\
\text { excursion }\end{array}$ & Protrusion \\
\hline $\begin{array}{l}\text { Control group, } \\
30-57 \text { yrs }\end{array}$ & $51.36 \pm 5.35$ & $51.37 \pm 5.34$ & $52.43 \pm 5.33$ & $10.59 \pm 2.09$ & $10.59 \pm 1.89$ & $11.12 \pm 2.04$ \\
\hline $\begin{array}{l}\text { Myofascial pain group, } \\
29-52 \text { yrs }\end{array}$ & $42.64 \pm 8.60$ & $48.01 \pm 8.43$ & $49.19 \pm 8.58$ & $9.89 \pm 2.10$ & $10.01 \pm 2.56$ & $9.12 \pm 2.15$ \\
\hline
\end{tabular}

In spite of these findings, they could not conclude that measurements of mandibular movements could discriminate one group (TMD patients) from the other (asymptomatic subjects), because the mean ranges of movements of the majority of TMD patients were measured in clinically normal values. es. d. Even though more than $90 \%$ of the patients could attain a mouth opening of $35 \mathrm{~mm}$ or more, the mean maximal mouth opening of the patients was smaller than that of control subjects, as was the joint mobility. The mean maximal movement ranges were:

Table 3. Mean maximal movement ranges of patients with reducing and non-reducing disk displacement (10)

\begin{tabular}{lcc|ccc} 
& Mean age & $\begin{array}{c}\text { Mouth } \\
\text { opening } \mathrm{mm}\end{array}$ & $\begin{array}{c}\text { Lateral } \\
\text { excursion to } \\
\text { affected side } \\
\text { mm }\end{array}$ & $\begin{array}{c}\text { Lateral } \\
\text { excursion to } \\
\text { unaffected } \\
\text { side mm }\end{array}$ & $\begin{array}{c}\text { Protrusion } \\
\text { mm }\end{array}$ \\
$\begin{array}{l}\text { Control gr. } \\
\begin{array}{l}\text { Reducing disc displacement } \\
\text { group }\end{array}\end{array}$ & $58.9 \mathrm{yrs}$ & $47.9 \pm 7.2$ & $9.1 \pm 3.6$ & $8.6 \pm 3.9$ & $8.0 \pm 2.7$ \\
$\begin{array}{l}\text { Non-reducting disc } \\
\text { displacement group }\end{array}$ & $58.2 \mathrm{yrs}$ & $42.1 \pm 6.8$ & $8.0 \pm 2.8$ & $7.6 \pm 3.1$ & $7.3 \pm 2.9$ \\
\hline
\end{tabular}


Vassil Svechtarov, Miriana Hristova, Savina Nencheva-Svechtarova

\section{RATIO BETWEEN VERTICAL AND THE HORIZONTAL RANGE OF MOTION (ROM)}

The ratio between the vertical and the horizontal ROM is used to predict the vertical ROM on the basis of the horizontal ROM and vice versa. Hochstedler et al. (16) suggested using the ratio of maximum opening to lateral movement, instead of the simple MMO measurement, to evaluate TMJ function. This ratio was found to be 4.4:1 in normal subjects. However, the authors stated that in patients with intracapsular and extracapsular disorders, both components of the ratio might be affected similarly, with the risk that limitations in all movements might yield a "normal" ratio, even though dysfunction was present. Dijkstra et al. (11) found that this ratio was from 6.0:1 to 6.6:1 (on an individual basis from 3.6 to 15.5), rather than $4: 1$ as suggested in the literature, and concluded that the ratio had poor predictive value.

\section{CONCLUSION}

The most common values of the normal movement range established for adults in the literature are as follows: mouth opening: from 35 to $60 \mathrm{~mm}$, average $53.3-58.6 \mathrm{~mm}$, lateral excursions and protrusion: from 7 to $10 \mathrm{~mm}$. Differences across studies are mainly due to methodological discrepancies; the anthropometric data in the studies is directly relevant to the racial profile that makes up a population group. Studies evaluating lateral and protrusive movements in asymptomatic and symptomatic subjects have suggested varied results. In the majority of studies lateral movements are ranged from 7 to 10 $\mathrm{mm}$ or from 8.7 to $11.1 \mathrm{~mm}$.

Mandibular movement ranges vary greatly from one subject to another and their numerical values are not indicators of dysfunction unless they are associated with pain or other symptoms. Their evaluation is recommended by many authors as a diagnostic criterion in the assessment of temporomandibular disorders. Early recognition of limited or increased mandibular movements is necessary for a prompt and efficient approach to diagnosis and to plan out the treatment options. Knowing numerical values of the normal range of mandibular movements serve as a guide for treatment and diagnosis of diseases which directly or indirectly affect jaw movements.

\section{REFERENCES}

1. Agerberg G. Maximal mandibular movements in young men and women. Sven Tandlak Tidskr. 1974; 67:81-100.

2. Alpaslan C, JC Türp, T Gerds. Is there a greater mandibular movement capacity towards the left? Verification of an observation from 1921. J Oral Rehab. 04/2005; 32(4):242-7.

3. Badel T, J Pandurić, M Marotti, I Krolo. Clinical Investigation of Temporomandibular Joint Arthrosis Frequency in Young Males. Acta Stomatol Croat. $2006 ; 40(1): 46-55$.

4. Blečić N, Uhač I, Muhvić MU, Kovač Z, Leović D. Vukšić-Mihaljević Ž, Lisko D. Mandibular movements in patients with masticatory myofascial pain dysfunction. Protetyka stomatologiczna. 2005;5:111-112.

5. Bumann A, U Lotzmann. TMJ Disorders and Orofacial Pain. The Role of Dentistry in a Multidisciplinary Diagnostic Approach. Stuttgart: Georg Thieme Verlag; 2002.

6. Buschang PH, Throckmorton GS, Travers KH, Hayasaki H. Incisor and mandibular condylar movements of young adult females during maximum protrusion and lateratrusion of the jaw. Arch Oral Biol, 2001;46:39-48.

7. Celic R, V Jerolimov, D Knezovic, Relationship of slightly limited mandibular movements to temporomandibular disorders. Braz Dent J. 2004;15(2):151-154.

8. Celic R, V Jerolimov, DK Zlataric, B Klaic. Measurement of Mandibular Movements in Patients with Temporomandibular Disorders and in Asymptomatic Subjects (Croatia). Coll. Antropol. 2003;(27) Suppl. 2:43-49.

9. Cortese SG, Oliver LM, Biondi AM. Determination of range of mandibular movements in adults without TMD. J Craniomandib Pratt. 2007; 25: 200-205.

10. De Leeuw R, G Boaring, B Stegenga, LGM de Bont, Clinical Signs of TMJ Osteoarthrosis and Internal Derangement 30 Years After Nonsurgical Treatment. J Orofacial Pain. 1994; 8:18-24.

11. Dijkstra PU, TJ Kropmans, B Stegenga, LG de Bont, Ratio between vertical and horizontal mandibular range of motion. J Oral Rehab. 1998; 25(5):353-7.

12. Dworkin S, LeResche L. Research diagnostic criteria for TMD: review, criteria, examinations and 
Mandibular range of motion and its relation to temporomandibular disorders

specifications, critique. J Craniomandib Disord. 1992;6(4):301-55.

13. Farkas L, M Katic, C Forrest, International Anthropometric Study of Facial Morphology in Various Ethnic Groups/Races, J Craniofac Surg. 2005;16(4):615-46.

14. Gallagher C, Gallagher V, Whelton H, Cronin M. The normal range of mouth opening in an Irish population. J Oral Rehab. 2004;31(2):110-16.

15. Hirsh C, John MT, Lautensclagher C, List T: Mandibular jaw movement capacity in 10-17 year-old children and adolescents: normative values and the influence of gender, age and temporomandibular disorders. Eur J Oral Sci. 2006;114:465-70.

16. Hochstedler JL, Allen JD, Follmar MA. Temporomandibular joint range of motion: a ratio of interincisal opening to excursive movement in a healthy population. Cranio. 1996;14(4):296-300.

17. Ingervall $\mathrm{B}$, Variation of the range of movement of the mandible in relation to facial morphology in young adults. Scand J Dent Res. 1971;79(2):133-40.

18. Kardari Z, Mandibular and condylar movements in children and adults. A trial on kinematic parameters and their association with individual characteristics. PhD, Regensburg, 2011.

19. Kitsoulis P, A Marini, K Iliou, V Galani, A Zimpis, P Kanavaros, G Paraskevas. Signs and Symptoms of Temporomandibular Joint Disorders Related to the Degree of Mouth Opening and Hearing Loss. BMC Ear, Nose and Throat Disorders, 2011;11(5):1-8.

20. Landtwing K. Evaluation of the normal range of vertical mandibular opening in children and adolescents with special reference to age and stature. J Maxillofac Surg. 1978;6:157-62.

21. Lund J, Widmer C, Feine J. Validity of Diagnostic and Monitoring Tests Used for Temporomandibular Disorders. J Dent Res. 1995;74(4):1133-1143.

22. Mezitis M, Rallis G, Zachariades N. The normal range of mouth opening. J Oral Maxillofac Surg. 1989;47:1028-9.

23. Okeson, JP. Management of temporo- mandibular disorders and occlusion. St Louis: Mosby Year Book; 2003.

24. Piehslinger E, Celar A, Schmid-Schwap M, Slavicek R. Orthopedic jaw movement observations. Part III: The quantitation of mediotrusion. Cranio. 1994;12:33-37.
25. Placko G, Bellot-Samson V, Brunet S, et al. Normal mouth opening in the adult French population. Rev Stomatol Chir Maxillofac. 2005;106(5):267-71.

26. Poveda-Roda R, Bagán JV, Sanchis JM, Carbonell E. Temporomandibular disorders. A case-control study. Med Oral Patol Oral Cir Bucal. 2012 Sep 1; 17 (5):794-800.

27. Reicheneder CA, Proff P, Baumert U, Gedrange T. Growth-related differences in maximum laterotrusion and retrusion between children and adults. Angle Orthod, 2009;79:265-270,

28. Rieder CE. Maximum mandibular opening in patients with and without a history of TMJ dysfunction. J Prosthet Dent. 1978;39:441-446.

29. Rosenbaum M. The feasibility of a screening procedure regarding temporomandibular joint dysfunction. Oral Surg. 1975;39:382-389.

30. Scavone H, Trevisan H, Garib DG, Ferreira FV. Facial profile evaluation in Japnese-Brazilian adults with normal occlusions and well-balanced faces. Am J Orthod Dentofacial Orthop. 2006;129(6):721-25.

31. Travell J. Temporomandibular joint dysfunction. Temporomandibular joint pain referred from muscles of the head and neck. J Prosth Dent. 1960;10:745-763.

32. Travers KH. Buschang PH. Hayasaki H. Throckmorton, G.S. Associations between incisor and mandibular condylar movements during maximum mouth opening in humans. Arch Oral Biol. 2000;45:267-275.

33. Uzunov R, Hristova M, Ivancheva V, Svechtarov $\mathrm{V}$, Nencheva S. The range of inter-incisal opening among the Bulgarian population. Praemedicus. 2013;vol.29:60-63.

34. Yao KT, CC Lin, CH Hung, Maximum mouth opening of ethnic Chinese in Taiwan. J Dent Sci. 2009;4(1):40-44. 